\title{
Thin excuses for French nuclear tests
}

The government of France has given thin excuses for its weapons tests; the greatest danger lies in the precedents these tests will provide for the other black sheep who may want to join the planned Comprehensive Test-Ban Treaty.

St AugustinE's prayer, "Lord, make me chaste, but not yet!", applies to France. The international row over the French proposal to test a series of nuclear weapons in the Pacific is inevitable and proper, but the grounds for opposing the testing programme should be clear - and clearer than they have been to the crowds gathered to make noise outside French embassies in the past few weeks. Importantly, this is not an environmental issue in the ordinary meaning of that term. The tests will be underground, and past weeks will have impressed on those responsible the need than not a microcurie of radioactivity should escape from them. It is also important that France is not alone in earning censure; China carried out a nuclear test a few weeks ago without attracting crowds outside its embassies. The real objection to what China and France are about is that they provide awkward precedents for what may happen in the years that follow the signature next year of a Comprehensive Test-Ban Treaty (CTB).

True to form, China has given no explanation of its motives for continued testing. Under pressure, President Jacques Chirac has given two excuses: the tests, he says, are necessary to verify that weapons in the existing stockpile will still explode after lying on the shelf for some time, and it is also necessary to collect data for the development of the computer codes needed for the design of weapons in the future. (Chirac notes wistfully that six of the eight planned tests would not be required if only the United States shared information as freely with France as with Britain, without reference to the Ottawa agreement of 1943 by which Britain and the United States agreed a perpetual partnership in the exploitation of nuclear energy, and to the congressional laws by which the US administration is prohibited from sharing military nuclear technology otherwise.) Both explanations are thin, to say the least. The worry is that, if France can make them now, it (or some other would-be nuclear power) may choose to make them after the CTB comes into force.

The need to collect data for computer codes is overstated. For exactly fifty years, as it happens, the computer modelling of nuclear explosions has been one of the best supported technical art forms. For many years, the United States restricted the export of Cray computers as jealously as if they were fissile material just because of their usefulness in simulating nuclear explosions, but that horse has long since bolted. It is unthinkable that French weapons designers have only lately woken up to the utility of computer codes in their craft, or that past tests have failed to yield the data by which the necessary parameters can be determined. Either Chirac has been hoodwinked by his technical people, or he has decided that a show of Gaullist intransigence would be appropriate at the outset of his presidency.

The business of the ageing of nuclear weapons raises a different issue. Fission bombs have as components neutron sources built around relatively short-lived radioactive elements such as protoactinium, which evidently must be renewed from time to time. Similarly, hydrogen bombs use tritium, with a half-life of a dozen years or so, which must also be refreshed. But none of that demands great technical insight. The erosion with the passage of time of the military's confidence in a nuclear stockpile is something else.

This is a psychological matter, but an important one. If, with a CTB in force, the military become less sure of their nuclear weapons as time passes, they will be less inclined to rely on them as strategic weapons, with the result that they will inch along the road to a world without nuclear weapons. That process will not be quick, and would be instantly interrupted by a violation of the treaty, but it is one of the powerful reasons why the non-nuclear signatories of the Non-Proliferation Treaty agreed in April that the promise of the CTB would cement their adherence to this cause. Chirac's generals will eventually have to live with the uncertainties the CTB will bring them. It would have been better to start them on the road right now.

\section{Genetics brought to book}

The British House of Commons has produced a telling document on the future of genetics.

THE Mother of Parliaments, as the British parliament likes to call itself, has been well served by the House of Commons Select Committee on Science and Technology, whose report on human genetics is published this week (see page 202). The committee's conclusions are panicfree, the arguments by which it reaches them are intelligent, its findings are plainly based on a huge amount of work and it repeat-edly emphasizes that its capacity to foretell the future is hampered by the speed with which 